\title{
Produção de ácidos graxos voláteis e contagem de protozoários ruminais em bovinos suplementados com gordura
}

Geraldo BALIEIRO-NETO' Laércio MELLOTI ${ }^{2}$

\section{Correspondência para:} GERALDOBALIEIRO NETO

Av. Bandeirantes, 2419-Bairro Vila Virginia 14030-670 - Ribeirão Preto - SP geraldobalieiro@aptaregional.sp.gov.br

Recebido para publicação: 04/01/2006 Aprovado para publicação: 07/02/2007

\author{
1 - Pesquisador Científico da Agência Paulista de Tecnologia dos \\ Agronegócios - APTA Regional Centro-Leste, Ribeirão Preto - SP \\ 2 - Professor Aposentado da Faculdade de Medicina Veterinária e Zootecnia \\ da Universidade de São Paulo
}

\section{Resumo}

Os efeitos da utilização de sebo (SEBO) sobre contagem de protozoários ruminais e produção de ácidos graxos voláteis foram estudados em um experimento de Quadrado Latino 3 x 3, utilizandose 6 fêmeas bovinas ( $480 \mathrm{~kg}$ de P.V.) dotadas de cânulas ruminais, para avaliar três dietas, sem ou com 3 ou $6 \%$ de sebo (SEBO). As coletas de líquido ruminal foram feitas no $21^{\circ}$ dia de cada subperíodo experimental às $0,1,2,3,4,6$ e 8 horas após a $1^{a}$ refeição. Houve redução dos protozoários totais, redução do conteúdo de ácidos graxos totais e mudança no padrão de fermentação com aumento na proporção de ácido propiônico e redução de ácido butírico nas dietas com $6 \%$ de sebo (SEBO).

\section{Introdução}

Animais de alta produção podem sofrer balanço energético negativo durante certas fases fisiológicas em que o consumo de matéria seca é reduzido. Como a quantidade de ração concentrada fornecida a animais de alta produção apresenta um limite fisiológico, a partir do qual acarretaria problemas metabólicos, a utilização de fontes de gordura representa uma opção para reduzir o desequilíbrio energético, incrementando a densidade energética da dieta e mantendo um balanço mais adequado entre carboidratos estruturais e não estruturais. Além disso, a gordura dietética pode otimizar a utilização de energia digestível devido a redução de perdas pela produção de gás metano ${ }^{1}$ e menor gasto energético para síntese de gordura do leite ${ }^{2}$.

Entretanto, as gorduras dietéticas podem causar alteração no metabolismo ruminal. Alguns autores citam efeito de toxicidade da gordura dietética para protozoários e bactérias gram-positivas, enquanto bactérias gram-negativas seriam mais resistentes ${ }^{3}$. Como protozoários são predadores de bactérias, a eliminação dos mesmos pode promover um aumento no número de bactérias e alterações da ecologia e metabolismo ruminal, podendo alterar o conteúdo total e proporções entre os ácidos graxos voláteis. A investigação e entendimento destas ocorrências são importantes para o êxito da utilização de gordura na dieta dos animais.

Este trabalho teve por objetivo analisar a produção de ácidos graxos voláteis e proceder a contagem de protozoários ruminais em fêmeas Holandesas dotadas de cânulas ruminais recebendo suplementação concentrada com diferentes níveis de sebo.

\section{Materiais e Método}

O trabalho foi realizado nas instalações da Faculdade de Medicina Veterinária e Zootecnia da Universidade de São Paulo, FMVZ - USP, utilizando-se seis fêmeas bovinas com média de $480 \mathrm{~kg}$ de peso vivo, portadoras de fistula ruminal. Foi testado o efeito de três níveis de sebo na 
dieta total $(0,3$ ou $6 \%)$ sobre a produção de Ácidos Graxos Voláteis (AGVs), população de protozoários ruminais, $\mathrm{pH}$ e taxa de passagem. Foi utilizado o delineamento experimental em Quadrado Latino $3 \times 3$, com dois grupos de três animais em três subperíodos experimentais de 28 dias de duração. As dietas foram isoprotéicas e tiveram a mesma proporção concentrado/volumoso, sendo o feno de Tifton (Cynodon dactylon) o único volumoso representando $60 \%$ das mesmas.

Nas duas primeiras semanas os animais permaneceram em fase de adaptação ao alimento, sendo as dietas formuladas para conter $13 \%$ de proteína bruta $^{4}$.

Foram realizadas medidas repetidas no tempo para coletas de líquido ruminal ao longo do dia. As amostras foram coletadas em três pontos (antro e sacos ventrais anterior e posterior) e realizadas às 0h, 1h, 2h, 3h, 4h, 6h e $8 \mathrm{~h}$ após o arraçoamento matinal realizado às 8:00 h. A coleta referente à $0 \mathrm{~h}$ foi realizada imediatamente antes dos animais receberem a primeira refeição. Logo após as coletas, $100 \mathrm{ml}$ de fluído ruminal foram utilizados para a determinação do $\mathrm{pH}$ em potenciômetro digital portátil da marca Corning modelo PS30, calibrados com soluções tampão (Procyon Intrumentação Científica Ltda.) de pH 4,0 e 7,0 .

Para a determinação de AGVs uma alíquota de aproximadamente $100 \mathrm{ml}$ de líquido ruminal foi transferida para um tubo de centrífuga e centrifugada a $3.500 \mathrm{rpm}$ por 15 minutos. Transferiu-se $1 \mathrm{ml}$ do sobrenadante para um tubo de ensaio arrolhado e adicionou-se $0,2 \mathrm{ml}$ de ácido fórmico, armazenando-o em congelador a $-20^{\circ} \mathrm{C}$ até o momento da análise. A determinação dos AGVs contidos no líquido ruminal foi realizada através de cromatografia gasosa, segundo método preconizado por Erwin, Marco e Emery ${ }^{5}$, em laboratório da Faculdade de Medicina Veterinária e Zootecnia da USP no Campus de Pirassununga, SP. Para tal foi utilizado um cromatógrafo a gás modelo CG 37-D da empresa Instrumentos Científicos C.G. Ltda, equipado com coluna de vidro de 4 pés de comprimento e $1 / 8$ de polegada de diâmetro empacotada com Carbopack. Os gases utilizados foram: nitrogênio, como gás de arraste na vazão de 30 mililitros por minuto; oxigênio, como gás comburente na vazão de $400 \mathrm{ml} / \mathrm{min}$ e hidrogênio, como gás combustível na vazão de $40 \mathrm{ml} / \mathrm{min}$. As temperaturas utilizadas para operação do vaporizador, coluna de separação e detector de ionização de chamas foram de 195, 120 e 205 graus Celsius, respectivamente. Foram preparadas soluções $0,1 \mathrm{~N}$ dos ácidos acético, propiônico, butírico, isobutírico, 2metilbutírico, valérico e isovalérico, a quais tiveram suas respectivas normalidades determinadas com maior acuidade através da titulação com uma solução padronizada de $\mathrm{KOH}$, de forma a produzir uma solução padrão de AGVs de concentração conhecida. Para cada determinação foram injetados 1,0 microlitro de amostra, sendo o resultado obtido através de um integrador que utilizou a solução padrão como base para o cálculo das concentrações de AGVs da amostra. O número de repetições por amostra foi aquele necessário para que a diferença entre as leituras fosse inferior a 5\%. A solução padrão foi injetada a cada 10 injeções sucessivas de amostras, tentando-se evitar, desta maneira, possíveis distorções das leituras em função da contaminação da coluna.

Os cálculos foram realizados comparando-se as amostras a uma solução padrão contendo $63,5 \%$ de ácido acético $\left(\mathrm{C}_{2}\right), 21,0 \%$ de ácido propiônico $\left(\mathrm{C}_{3}\right), 9,0 \%$ de ácido butírico $\left(\mathrm{C}_{4}\right)$ e o restante $(6,5 \%)$ de isoácidos (isobutírico, 2-metilbutírico, valérico e isovalérico). Assim como a amostra de líquido ruminal, a solução padrão também foi adicionada de $0,2 \mathrm{ml}$ de ácido fórmico P.A. para cada $1 \mathrm{ml}$ de solução de AGVs de concentração conhecida.

Para a contagem de protozoários as coletas foram feitas $0,2,4,6$ e 8 horas após o arraçoamento matinal. As amostras foram 
coletadas espremendo-se com as mãos o conteúdo ruminal. Após a obtenção deste material, $5 \mathrm{ml}$ foram transferidos para tubos contendo $5 \mathrm{ml}$ de formaldeido $40 \%$ na proporção 1:1, posteriormente foi realizada a contagem de protozoários com auxílio de microscópio.

A determinação do volume de líquido e da taxa de passagem de líquido pelo rúmen foi realizada através do polietilenoglicol de peso molecular 4.000 (PEG 4.000). Às 7:00 h do $28^{\circ}$ dia de cada período de adaptação, foram introduzidos, através da cânula ruminal $300 \mathrm{~g}$ de PEG (Carbowax 4.000, marca Synth) previamente diluídos em aproximadamente $500 \mathrm{ml}$ de água, misturando-se em seguida o marcador com o conteúdo ruminal manualmente. Amostras de líquido para determinações das concentrações de PEG foram tomadas às 0h, 1h, 3h, 6h, 9h, 12h e 24 horas. A amostra referente ao tempo zero foi coletada imediatamente antes da introdução do PEG, sendo a água e a primeira refeição do dia, fornecidas após a coleta da $1 \mathrm{~h}$, ou seja, às 8:00 hs, já que os animais foram privados de beber água e se alimentar desde às 0:00 h (meia-noite) do mesmo dia. O líquido ruminal foi centrifugado por 10 minutos a $3.500 \mathrm{ppm}$ no local da coleta e o sobrenadante armazenado sob refrigeração até a realização das análises. A determinação da concentração de PEG foi realizada segundo o método preconizado por Hyden ${ }^{6}$.

Os resultados foram analisados através do programa computacional Statistical Analysis System ${ }^{7}$, sendo submetidos a análise de variância pelo procedimento GLM (PROC GLM).

\section{Resultados e Discussão}

Houve redução da produção de ácidos graxos totais logo após o arraçoamento matinal (Tabela 1). Ocorreu uma mudança no padrão de fermentação com incremento nas porcentagens de ácido propiônico (Tabela 3) e redução de ácido butírico (Tabela 4) em dietas com maior porcentagem de gordura.

Os efeitos de queda no conteúdo de ácidos graxos voláteis totais e na proporção acetato-propionato ocorreu mesmo em dieta contendo $60 \%$ de volumoso, provavelmente devido aos valores de $\mathrm{pH}$ terem favorecido a lipólise, contribuindo para presença de ácidos graxos livres no meio ${ }^{8}$. Os valores de $\mathrm{pH}$ foram de 6,57; 6,42 e 6,50 para dietas com 0,3 e $6 \%$ de sebo, respectivamente. Ácidos graxos livres no ambiente ruminal são tóxicos as bactérias gram-positivas, em especial celulolíticas e metanogênicas ${ }^{9}$ e provavelmente inibiram a metanogênese, efeito este associado ao aumento na produção de ácido propiônico (Tabela 3) e diminuição no acetato (Tabela 2) e butirato (Tabela 4). Efeitos similares utilizando ácidos graxos insaturados foram relatados por Demeyer, Van Nevel e Henderickx ${ }^{10}$, Demeyer et al. ${ }^{11}$ e Prins, Van Nevel e Demeyer ${ }^{12}$, sendo atribuídos ao efeito tóxico dos mesmos. A ocorrência de efeitos similares sobre o padrão de fermentação dos AGVs com a utilização de ácidos graxos predominantemente saturados, encontrados neste trabalho, sugere a ocorrência de alta atividade lipolítica.

Os resultados encontrados neste trabalho estão de acordo com o trabalho de Emanuelson, Murphy e Sindberg ${ }^{13}$. Um trabalho de Chalupa et al. ${ }^{14}$ também demonstrou decréscimo na proporção molar acetato/propionato no rúmen de novilhas holandesas suplementadas com $8 \%$ de sebo, ao passo que esta proporção passou a quase normal quando o lipídio foi fornecido na forma de sabão de cálcio. Este resultado mostra a importância da dissociação dos triglicerideos sobre seus efeitos no rumen. Assim sendo, dietas com maior proporção de concentrado e valores inferiores de $\mathrm{pH}$ ruminal podem alterar a atividade lipolítica e consequentemente, o efeito da suplementação com gordura.

Observou-se uma redução marcante sobre a população de protozoários (Tabela 5). Este efeito deve-se principalmente a toxicidade de ácidos graxos livres no meio, 
no entanto, podem ter sido favorecidos pela adsorção de partículas, tornando-as indisponíveis aos protozoários, e pelo fato de que lipídios não fornecem energia para crescimento microbiano. Este efeito está de acordo com vários autores ${ }^{1,15}$.

Os protozoários exercem importante papel na degradação de proteínas e amidos.

Tabela 01 - Efeitos de diferentes níveis de adição de sebo sobre as concentrações de $A G V s\left(C_{2}+C_{3}+C_{4}\right)$ no líquido ruminal (mM), em diferentes horas de amostragem, coeficientes de variação e probabilidades estatísticas. Pirassununga, SP, 1998

\begin{tabular}{|c|c|c|c|c|c|c|c|c|}
\hline \multirow{2}{*}{$\begin{array}{c}\text { MS } \\
\text { Tempo(Hs) }\end{array}$} & \multicolumn{3}{|c|}{$\%$ de Gordura } & \multirow[t]{2}{*}{$\mathrm{CV}$} & \multicolumn{2}{|c|}{ Probabilidade } & \multirow[t]{2}{*}{ Equação ${ }^{1}$} & \multirow[t]{2}{*}{$\mathrm{R}^{2}$} \\
\hline & 0 & 3 & 6 & & $\mathrm{~L}$ & DL & & \\
\hline 0 & 72,791 & 56,310 & 57,284 & 30,30 & 0,026 & 0,556 & $A G V s=73,613-2,557 G$ & 0,346 \\
\hline 1 & 73,142 & 68,996 & 64,381 & 15,52 & 0,199 & 0,949 & & \\
\hline 2 & 69,424 & 74,683 & 57,970 & 18,16 & 0,080 & 0,057 & & \\
\hline 3 & 65,707 & 71,125 & 60,406 & 19,10 & 0,440 & 0,191 & & \\
\hline 4 & 60,800 & 69,826 & 58,007 & 20,45 & 0,640 & 0,070 & & \\
\hline 6 & 57,221 & 61,013 & 58,974 & 11,63 & 0,632 & 0,367 & & \\
\hline 8 & 62,007 & 62,543 & 55,007 & 19,27 & 0,315 & 0,495 & & \\
\hline
\end{tabular}

Números em negrito indicam que houve diferença estatisticamente significativa $(\mathrm{P}<0,05)$ para efeito linear $(\mathrm{L})$ ou desvio da linearidade $(\mathrm{DL})$. ${ }^{1} \mathrm{AGVs}=\mathrm{C}_{2}+\mathrm{C}_{3}+\mathrm{C}_{4} ; \mathrm{G}=\%$ de gordura

Tabela 02 - Efeitos de diferentes níveis de adição de sebo sobre as porcentagens molares de acetato (\% molar) no líquido ruminal, coeficientes de variação e probabilidades estatísticas. Pirassununga, SP, 1998

\begin{tabular}{|c|c|c|c|c|c|c|c|c|}
\hline \multirow{2}{*}{$\begin{array}{c}\text { MS } \\
\text { Tempo (Hs) }\end{array}$} & \multicolumn{3}{|c|}{$\%$ de Gordura } & \multirow[t]{2}{*}{$\mathrm{CV}$} & \multicolumn{2}{|c|}{ Probabilidade } & \multirow[t]{2}{*}{ Equação $^{1}$} & \multirow[t]{2}{*}{$\mathrm{R}^{2}$} \\
\hline & 0 & 3 & 6 & & $\mathrm{~L}$ & $\mathrm{DL}$ & & \\
\hline 0 & 70,234 & 71,150 & 69,361 & 3,735 & 0,362 & 0,193 & & \\
\hline 1 & 66,433 & 71,667 & 70,324 & 9,339 & 0,351 & 0,362 & & \\
\hline 2 & 72,481 & 72,138 & 70,116 & 3,934 & 0,159 & 0,542 & & \\
\hline 3 & 72,169 & 70,921 & 69,781 & 3,788 & 0,080 & 0,959 & & \\
\hline 4 & 72,971 & 71,698 & 69,548 & 3,949 & 0,022 & 0,687 & $A=73,117-0,57 G$ & 0,259 \\
\hline 6 & 72,105 & 70,828 & 70,136 & 3,797 & 0,094 & 0,752 & & \\
\hline 8 & 71,720 & 70,707 & 68,779 & 4,555 & 0,084 & 0,732 & & \\
\hline
\end{tabular}

Números em negrito indicam que houve diferença estatisticamente significativa $(\mathrm{P}<0,05)$ para efeito linear $(\mathrm{L})$ ou desvio da linearidade $(\mathrm{DL})$. ${ }^{1} \mathrm{~A}=$ acético $\mathrm{G}=\%$ de gordura

Tabela 03 - Efeitos de diferentes níveis de adição de sebo sobre as porcentagens molares de propionato (\% molar) no líquido ruminal, coeficientes de variação e probabilidades estatísticas. Pirassununga, SP, 1998

\begin{tabular}{ccccccccc}
\hline MS & \multicolumn{3}{c}{ \% de Gordura } & \multicolumn{1}{c}{ CV } & \multicolumn{2}{c}{ Probabilidade } & Equação ${ }^{1}$ & R $^{2}$ \\
Tempo(Hs) & 0 & 3 & 6 & & $L$ & DL & \\
\hline 0 & 17,179 & 16,236 & 19,800 & 15,51 & 0,065 & 0,062 & & \\
1 & 14,634 & 16,218 & 19,676 & 17,55 & 0,0004 & 0,252 & $\mathrm{P}=14,322+0,840 \mathrm{G}$ & 0,513 \\
2 & 15,666 & 16,088 & 20,060 & 15,74 & 0,002 & 0,082 & $\mathrm{P}=15,075+0,732 \mathrm{G}$ & 0,460 \\
3 & 15,489 & 16,757 & 20,220 & 15,80 & 0,001 & 0,212 & $\mathrm{P}=15,123+0,788 \mathrm{G}$ & 0,517 \\
4 & 15,246 & 16,305 & 20,439 & 16,88 & 0,0005 & 0,087 & $\mathrm{P}=14,733+0,865 \mathrm{G}$ & 0,555 \\
6 & 15,537 & 17,091 & 20,102 & 15,72 & 0,0005 & 0,328 & $\mathrm{P}=15,294+0,76 \mathrm{G}$ & 0,481 \\
8 & 15,334 & 16,605 & 20,864 & 18,69 & 0,003 & 0,230 & $\mathrm{P}=14,852+0,905 \mathrm{G}$ & 0,476 \\
\hline
\end{tabular}

Números em negrito indicam que houve diferença estatisticamente significativa $(\mathrm{P}<0,01)$ para efeito linear $(\mathrm{L})$ ou desvio da linearidade $(\mathrm{DL})$.

${ }^{1} \mathrm{P}=$ propiônico $\mathrm{G}=\%$ de gordura 
Tabela 04 - Efeitos de diferentes níveis de adição de sebo sobre as porcentagens molares de butirato (\% molar) no líquido ruminal, coeficientes de variação e probabilidades estatísticas. Pirassununga, SP, 1998

\begin{tabular}{ccccccccc}
\hline MS & \multicolumn{3}{c}{ \% de Gordura } & $\mathrm{CV}$ & \multicolumn{2}{c}{ Probabilidade } & Equação & $\mathrm{R}^{2}$ \\
Tempo $(\mathrm{Hs})$ & 0 & 3 & 6 & & $\mathrm{~L}$ & $\mathrm{DL}$ & & \\
\hline 0 & 12,585 & 12,612 & 10,837 & 12,22 & 0,078 & 0,235 & & \\
1 & 18,931 & 12,113 & 9,999 & 59,22 & 0,074 & 0,550 & & \\
2 & 11,851 & 11,772 & 9,823 & 13,83 & 0,024 & 0,180 & $\mathrm{~B}=12,163-0,338 \mathrm{G}$ & 0,305 \\
3 & 12,291 & 12,321 & 9,998 & 14,05 & 0,010 & 0,085 & $\mathrm{~B}=12,683-0,382 \mathrm{G}$ & 0,353 \\
4 & 11,782 & 11,995 & 10,011 & 13,11 & 0,028 & 0,092 & $\mathrm{~B}=12,148-0,295 \mathrm{G}$ & 0,253 \\
6 & 12,357 & 12,080 & 9,760 & 15,94 & 0,005 & 0,122 & $\mathrm{~B}=12,697-0.432 \mathrm{G}$ & 0,360 \\
8 & 12,945 & 12,686 & 8,394 & 27,58 & 0,012 & 0,137 & $\mathrm{~B}=13,617-0,758 \mathrm{G}$ & 0,373 \\
\hline
\end{tabular}

Números em negrito indicam que houve diferença estatisticamente significativa $(\mathrm{P}<0,05)$ para efeito linear $(\mathrm{L})$ ou desvio da linearidade $(\mathrm{DL})$.

${ }^{1} \mathrm{~B}=$ butírico $\mathrm{G}=\%$ de gordura

A defaunação pode acarretar mudança na composição da população bacteriana favorecendo espécies amilolíticas e proteolíticas por estas não serem ingeridas pelos protozoários, ou devido utilização dos mesmos substratos, e ao mesmo tempo pode prejudicar outras que dependem da ação dos protozoários sobre o controle da população de bactérias e quebra de alimentos. Desta forma, aparentemente bactérias amilolíticas e proteolíticas foram beneficiadas e as celulolíticas e metanogências prejudicadas, resultando em aumento de ácido propiônico e redução de acético e butírico.

Alguns autores sugerem que a defaunação ocasiona aumento da eficiência de crescimento microbiano, como resultado da diminuição de atividade predatória dos protozoários contra as bactérias, fazendo com que ocorra maior fluxo duodenal de nutrientes da dieta e aumento linear na taxa de passagem de fluido ruminal com o aumento de gordura na dieta ${ }^{1,16,17}$. Entretanto, os efeitos da suplementação de gordura sobre a taxa de passagem parecem estar relacionados a proporções entre concentrado/volumoso das dietas estudadas.

Os valores de volume de líquido ruminal foram de 60,83; 61,25 e 64,23 litros para animais recebendo 0, 3 e $6 \%$ de sebo, respectivamente. Os valores de fluxo de líquido por quilo de matéria seca consumida foram de 12,9; 13,4 e 13,7 litros e os valores de taxa de passagem de líquido ruminal foram de 8,$3 ; 7,5$ e 7,2\% por hora, respectivamente, para animais consumindo de 9,48; 8,69 e 8,52 kg de MS por dia, nos tratamentos com 0,3 e $6 \%$ de sebo, respectivamente.

Provavelmente a proporção fixa de $60 \%$ volumoso na dieta provocou baixa taxa de passagem podendo ter contribuído para ausência de efeito da gordura sobre a

Tabela 05 - Efeitos de diferentes níveis de adição de sebo sobre a contagem de protozoários ruminais $\left(\times 10^{8}\right)$, coeficientes de variação e probabilidades estatísticas. Pirassununga, SP, 1998

\begin{tabular}{ccccccccc}
\hline MS & \multicolumn{3}{c}{ \% de Gordura } & CV & \multicolumn{2}{c}{ Probabilidade } & Equação ${ }^{1}$ & $\mathrm{R}^{2}$ \\
Tempo (hs) & 0 & 3 & 6 & & $\mathrm{~L}$ & $\mathrm{DL}$ & & \\
\hline 0 & 202.8 & 170.0 & 60.5 & 55.15 & 0.003 & 0.248 & $\mathrm{P}=215,611-23,722 \mathrm{G}$ & 0,563 \\
2 & 187.0 & 199.8 & 45.6 & 56.72 & 0.0005 & 0.005 & $\mathrm{P}=214,833-23,555 \mathrm{G}$ & 0,527 \\
4 & 194.0 & 219.0 & 59.5 & 54.29 & 0.005 & 0.017 & $\mathrm{P}=224,750-22,416 \mathrm{G}$ & 0,436 \\
6 & 158.5 & 187.1 & 52.0 & 54.06 & 0.0045 & 0.0085 & $\mathrm{P}=185,805-17,750 \mathrm{G}$ & 0,389 \\
8 & 170.5 & 197.5 & 56.1 & 59.37 & 0.0223 & 0.0431 & $\mathrm{P}=198,555-19,055 \mathrm{G}$ & 0,327 \\
\hline
\end{tabular}

${ }^{1} \mathrm{P}=$ protozoários totais, $\% \mathrm{G}=$ porcentagem de sebo, $\mathrm{NS}=$ não significativo

${ }^{2}$ Números em negrito indicam que houve diferença estatisticamente significativa $(\mathrm{P}<0,05)$ para efeito linear $(\mathrm{L})$ ou desvio da linearidade $(\mathrm{DL})$ 
passagem de fluídos. Além disso, os valores observados podem ser explicados devido a redução da motilidade intestinal ocasionada pelo aumento da secreção do hormônio enterogastrona estimulada pela presença de lipídios no duodeno ${ }^{18}$. Esta distensão do trato digestivo inferior bloqueia a mobilidade do trato superior, sendo que uma pequena alteração no volume intestinal pode ter maior ação que grande alteração no volume do conteúdo ruminal ${ }^{18,19}$.

Sendo assim, mesmo com a redução no número de protozoários não foi encontrado efeito significativo sobre a taxa de passagem de líquidos, divergindo do resultado encontrado por Weisbjerg ${ }^{20}$, onde a taxa de passagem de fluído aumentou em níveis de sebo de 2 e $4 \%$, caindo para níveis normais com suplementação de $6 \%$.

A redução dos valores de taxa de passagem para menores valores de ingestão de MS é esperada, e certamente relaciona-se a reduções na ingestão de água, fluxo salivar e aumento no tempo de retenção da matéria seca no rúmen. Obviamente, se a taxa de passagem e o consumo de matéria seca forem reduzidos, a intenção em incrementar o fornecimento de energia aos animais através da suplementação de gordura pode fracassar. No entanto, esses efeitos indesejáveis parecem ter sido amenizados pelo parcelamento da dieta em quatro refeições diárias.

\section{Conclusão}

As dietas com sebo reduziram a concentração de ácidos graxos voláteis com aumento na proporção molar do propionato e redução nas proporções molares do acetato e butirato e a adição de 6\% de sebo na dieta provocou marcada redução na população de protozoários ruminais.

\section{Volatile fatty acids production and counting of protozoa ruminate in bovine supplemented with fat}

\section{Abstract}

Effects of tallow (Tallow) supplementation on counting of protozoa Fermentation rumen and production of volatile fatty acids were studied in a Latin Ruminants. Square $(3 \times 3)$ design, with six canulated heifers ( $480 \mathrm{~kg}$ body weight), to evaluate three diets, without or with 3 and $6 \%$ of tallow. Ruminal liquid collections were made at the twentieth first day of each experimental subperiod at $0,1,2,3,4,6$, and 8 hours after first meal. There was significant reduction of total protozoa in the rumen content and change in the fermentation with increase in the molar percentage of propionate and reduction in the molar percentage of butyrate at $6 \%$ of tallow.

\section{Referências}

1 DEMEYER, D. I.; VAN NEVEL, C. J. Transformations and effects of lipids in the rúmen: three decades of research at gent university. Archive Animal Nutrition, v. 48, p. $119-134,1995$.

2 PALMQUIST, D. L. The role of dietary fats in efficiency of ruminants. Journal of Nutricion, v. 124, p.1377, 1994. Suplemento 8.
3 IKWUEGBU, O. A.; SUTTON, J. D. The effect of varying the amount of linseed oil supplementation on rúmen metabolism in sheep. Br. J. Nutr. v. 48, n. 2, p. 365-375, 1982

4 NRC. Nutrient requeriments of dairy cattle. Washington: National Academy Press, 1989.

5 ERWIN, E. S.; MARCO, G. J.; EMERY, E. M. Volatile fatty acid analyses of blood and rúmen fluid by gas chromatography. Journal of Dairy Science, v. 44, n. 9, p. 1768-1771, 1961. 
6 HYDEN, S. A. A turbidometric method for the determination of higher polyethylene glycols in biological materials. K. Lantbr. Hogsk. Arbb., v. 22, p. 139-145, 1956.

7 SAS Institute Inc. SAS User's guide: statistics. ver. 5 ed.Cary, NC: SAS Institute, 1985.

8 JENKINS, T. C.; PALMQUIST, D. L. Effect of fatty acids or calcium soaps on rúmen and total nutrient digestibility of dairy rations. Journal Dairy Sci., v. 67, p. 978-986, 1984.

9 MACZULACK, A. E.; DEHORITY, B. A.; PALMQUIST, D. L. Effects of long-chain fatty acids on growth of rúmen bacteria. Appl. Environ. Microbiol., v. 42, p. 856,1981

10 DEMEYER, D. I.; VAN NEVEL, C. J.; HENDERICKX, H. Archiv Int. Physiol. Biochim. v. 74, p. 555, 1967.

11 DEMEYER, D. I. et al. The effects of unsaturated fatty acuds upon methone and propionicacid in the rumen. In: BLAXTER, K. L.; KIELANOWSKI, J.; THORBEK, G. (ed.) Energy Metabolism of Farm Animal. Newcastle upon Tyne: Oriel Press, 1969. p. 139-147.

12 PRINS, R.; VAN NEVEL, C.; DEMEYER, D. A. Van Leeuwenhoek Microb. Serol., v. 38, p. 281. 1972.

13 EMANUELSON, M.; MURPHY, M.; LINDBERG, J. E. Effects of heat-treated and untreated full-fat rapeseed and tallow on rúmen metabolism, digestibility, milk composition and milk yield in lactating cows. Animal Feed Science and Technology, v. 34. p. 291-309, 1991.

14 CHALUPA, W. et al. Journal Dairy Science, v. 68, p. 115, 1985. Supplement.

15 PALMQUIST, D. L. Suplementação de lipídios para vacas em lactação. In: PEIXOTO, A. M. Nutrição de Bovinos: conceitos básicos e aplicados. Piracicaba; FEALQ, 1993. p. 143.

16 CZERKAWSKI, J. W. et al. Changes in the rúmen metabolism os sheep given increasing amounts of linseed oil in their diet. Br. Journal of Nutrition, v. 34 , p. 25-43, 1975.

17 OHAJUREKA, O. A.; WU, Z.; PALMQUIST, D. L. Ruminal metabolism, fiber and protein digestion by lactating cows fed calcium soap or animal - vegetable fat. Journal of Dairy Science, v. 74, p. 2601-2609, 1991.

18 NICHOLSON, T.; OMER, S. A. The inhibitory effect of intestinal infusions of unsaturated long chain fatty acids on forestomach motility of sheep. Journal of Nutrition, v. 50, p. 149, 1983

19 LUCCl, C. S. Nutrição e manejo de bovinos leiteiros. São Paulo: Manole, 1997.

20 WEISBJERG, M. R.; BORSTING C. F.; HVELPLUND, T. The influence of tallow on rúmen metabolism, microbial biomass synthesis and fatty acid composition of bacteria and protozoa. Acta Agric. Scand.
Sect. A, Animal Science, v. 42, p. 106-114, 1992. 